\section{Response to: 'Risk of vascular disease with gout: overadjustment of the statistical analyses?' by van Durme et al}

We thank van Durme et al for their interest in our paper and for the opportunity to discuss these important methodological issues regarding possible overadjustment for chronic renal disease. ${ }^{1}$ However, there are a number of reasons that we would refute the suggestion of overadjustment in our analyses.

First, the definition of renal disease used as part of the Charlson comorbidity index (CCI), and thus the codes used to identify these conditions, was different to those used in our analysis. We were interested specifically in chronic kidney disease (CKD), defined as "kidney damage or glomerular filtration rate $<60 \mathrm{~mL} / \mathrm{min} / 1.73 \mathrm{~m}^{2}$ for 3 months or more, irrespective of

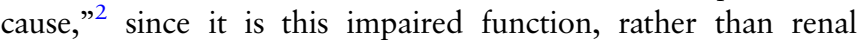
disease per se, that has been shown to be an independent risk factor for vascular disease. ${ }^{3}$ The Read codes supplied by Khan et $a l,{ }^{4}$ focus on a wider range of renal diseases including acute and chronic conditions, and those which cause deterioration in renal function and those which do not. In fact there was little overlap of Read codes used to identify renal disease according to the two definitions, (only 16 of 143 codes) and thus the two groups did not necessarily contain the same participants.

Second, the strength of this study is it's generalisability to, and focus upon, primary care patients with gout since the majority of patients with gout in the UK are managed in primary care. The multimorbid complexity of patients managed in this setting is continually increasing, ${ }^{56}$ and as such the statistical analyses used to examine epidemiological associations in these populations must reflect this. While this may be considered by some to introduce the possibility of overadjustment, we would contend that it allows for a more representative and clinically relevant assessment of risk, particularly as a statistically sound analysis without biological plausibility is of no value to practicing clinicians, and overadjustment bias tends to bias towards the null giving increased confidence in the significance of any association detected. ${ }^{7}$

However, to confirm the lack of overadjustment bias in our paper the analysis was repeated excluding CKD as a separate variable. The resulting HRs were unchanged (men: HR 1.06 95\% CI 1.01 to 1.12 ; women: HR $1.2595 \%$ CI 1.15 to 1.36 ).

In conclusion, rather than being considered an overadjustment, we feel that the CKD variable adds additional information about a common primary care comorbidity only minimally overlapping with the renal diseases identified as part of the CCI.
We hope that this will highlight the absence of overadjustment bias in our analyses, and the importance of testing a clinically valid model which must inevitably become more complex in order to accurately represent multimorbid primary care patients, and the benefits of which, particularly in this study, outweigh the very small risk of overadjustment bias towards the null.

Lorna Clarson, ${ }^{1}$ Samantha L Hider, ${ }^{1}$ John Belcher, ${ }^{1}$ Carl Heneghan, Edward Roddy, ${ }^{1}$ Christian D Mallen ${ }^{1}$

${ }^{1}$ Research Institute for Primary Care and Health Sciences, Keele University, Keele, UK ${ }^{2}$ Department of Primary Care Health Sciences, Oxford University, Oxford, UK

Correspondence to Dr Lorna Clarson, Research Institute of Primary Care and Health Sciences, Keele University, Keele ST5 5BG, UK;

I.clarson@keele.ac.uk

Competing interests None.

Provenance and peer review Commissioned; internally peer reviewed.

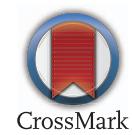

To cite Clarson L, Hider SL, Belcher J, et al. Ann Rheum Dis 2015;74:e10.

Received 8 October 2014

Accepted 9 October 2014

Published Online First 28 October 2014

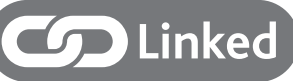

http://dx.doi.org/10.1136/annrheumdis-2014-206697

Ann Rheum Dis 2015;74:e10. doi:10.1136/annrheumdis-2014-206723

\section{REFERENCES}

1 van Durme CM, Spaetgens B, Boonen A, et al. Risk of vascular disease with gout: overadjustment of the statistical analyses? Ann Rheum Dis 2015;74:e9.

2 Levey AS, Eckardt KU, Tsukamoto Y, et al. Definition and classification of chronic kidney disease: a position statement from Kidney Disease: Improving Global Outcomes (KDIGO). Kidney Int 2005;67:2089-100.

3 Gansevoort RT, Correa-Rotter R, Hemmelgarn BR, et al. Chronic kidney disease and cardiovascular risk: epidemiology, mechanisms, and prevention. Lancet 2013;382:339-52.

4 Khan N, Perera R, Harper S, et al. Adaptation and validation of the Charlson Index for Read/OXMIS coded databases. BMC Fam Pract 2010;11;1.

5 Salisbury C, Johnson L, Purdy S, et al. Epidemiology and impact of multimorbidity in primary care: a retrospective cohort study. $\mathrm{Br} J$ Gen Pract 2011;61:e12-21.

6 Barnett K, Mercer SW, Norbury M, et al. Epidemiology of multimorbidity and implications for health care, research and medical education: a cross-sectional study. Lancet 2012;380:37-43.

7 Hernan MA, Hernandez-Diaz S, Werler MM, et al. Causal knowledge as a prerequisite for confounding evaluation: an application to birth defects epidemiology. Am J Epidemiol 2002;155:176-84. 